\title{
Development of an Electric Tri-Wheel Scooter
}

\author{
Ronaldo B. Asuncion, Warlito M. Galita \\ College of Industrial Technology, Bulacan State University City of Malolos, Bulacan, Philippines \\ Email: chloky23@yahoo.com
}

Received 25 May 2015; accepted 9 June 2015; published 15 June 2015

Copyright (C) 2015 by authors and OALib.

This work is licensed under the Creative Commons Attribution International License (CC BY). http://creativecommons.org/licenses/by/4.0/

(c) (i) Open Access

\section{Abstract}

The major objective of the study was to design and develop an electric tri-wheel scooter that would be used as a multi-purpose transportation medium in the Bulacan State University Main Campus. The project is developed to lessen the stress for people from all walks of life and circumstances. The project developed is made up of locally available materials. The project can be used indoors and outdoors, since it is designed to lessen the stress of some people who walk a great length. It is especially useful in indoor use, within the vicinity of a school, university, shopping and the like. It is intended for one rider only. It has 2 very important parts, the hub motor and the controller module. The hub motor is the one that drives the whole scooter assembly while the controller is the brain, commanding the hub, lights, sensors, etc. The scooter is powered using a 48 $V$ rechargeable battery and can run in forward and reverse directions. The scooter can fit through a normal size door and is equipped with a sensor that enables it to function only when a rider is on the platform. The project functioned according to expectations, being a cheaper and environmentfriendly alternative as compared with its commercially available counterparts. It also provided a cost-effective approach to providing individualized transport systems in a wide variety of applications.

\section{Keywords}

Electric, Tri-Wheel, Scooter, Transportation, Individualized Transport Systems, Electric Vehicles

Subject Areas: Education, Electric Engineering

\section{Introduction}

The history of transport is largely one of technological innovations. Advances in technology have allowed people to travel farther, explore more territory, and expand their influence over larger and larger areas. Even in ancient times, new tools such as foot coverings, skis, and snowshoes lengthened the distances that could be tra- 
veled. As new inventions and discoveries were applied to transport problems, travel time decreased while the ability to move more and larger loads increased. Innovation continues today, and transport researchers are working to find new ways to reduce costs and increase transport efficiency.

For thousands of years, humans transported themselves primarily by walking and running. As time passed, humans devised various methods of transportation. They learned to ride horses, elephants, cows, etc. Further advancements in technology have seen the inventions of fossil fuel vehicles called automobiles, thereby making modes of transportation faster and more convenient. However, they also leave behind a terrible trail of environmental damage since typical automobiles uses readily available fossil fuel from various sources.

Today, human conveyance plays an important role for obtaining a comfortable life. However, as the global human population grows more and more each day, more and more vehicles are added to the already burgeoning number of cars plying roads and main thoroughfares, thereby increasing the risks of air pollution. Passenger vehicles are a major pollution contributor, producing significant amounts of nitrogen oxides, carbon monoxide, and other pollution. In 2013, transportation contributed more than half of the carbon monoxide and nitrogen oxides, and almost a quarter of the hydrocarbons emitted into our air [1].

The health risks of air pollution are extremely serious. Poor air quality increases respiratory ailments like asthma and bronchitis, heightens the risk of life-threatening conditions like cancer, and burdens our health care system with substantial medical costs. Particulate matter is singlehandedly responsible for up to 30,000 premature deaths each year.

It is in this vein that alternative vehicles such as electric vehicles (EV) are being developed to being safe alternatives for modern human transportation. An EV, also referred to as an electric drive vehicle, uses one or more electric motors or traction motors for propulsion. An electric vehicle may be powered through a collector system by electricity from off-vehicle sources, or may be self-contained with a battery or generator to convert fuel to electricity [2]. EVs include road and rail vehicles, surface and underwater vessels, electric aircraft and electrically powered space vehicles. Electric vehicles are the major part of the e-mobility development which in literature is defined as following: "e-mobility (electric mobility) is a highly connective industry which focuses on serving mobility needs under the aspect of sustainability with a vehicle using a portable energy source and an electric drive that can vary in the degree of electrification" [3].

EVs first came into existence in the mid-19th century, when electricity was among the preferred methods for motor vehicle propulsion, providing a level of comfort and ease of operation that could not be achieved by the gasoline cars of the time. The internal combustion engine (ICE) has been the dominant propulsion method for motor vehicles for almost 100 years, but electric power has remained commonplace in other vehicle types, such as trains and smaller vehicles of all types.

It is in this light that the researchers opt to develop an electric scooter that can help ease the problems of conventional transportation by being a much cheaper alternative than gas powered scooters, not to mention the benefit of having no harmful carbon emissions. The study aims to underscore the importance of tapping alternative and clean energy sources to address various energy issues confronting the global environmental landscape. This burning desire of the researcher leads to the realization of the major objective of the study, which is to design and develop an Electric Tri-Wheel Scooter.

\section{The Research Problem}

The major objective of this undertaking is to design and develop an Electric Tri-Wheel Scooter. Specifically, the study aims to answer the following:

1) Develop a three-wheel scooter that has a forward and reverse operation.

2) Design an appropriate sensor circuit for proper positioning and safety of the rider.

3) Design a scooter that is easy to use and can be compared with other expensive brands available in the market today.

4) Determine the acceptability of the device based on the following criteria, namely:

a) Functionality;

b) Safety Features;

c) Durability; and

d) Aesthetics. 


\section{Methodology}

The framework that guided this study is depicted in the form of paradigm. This study followed the input, process and output (IPO) model (Figure 1).

The INPUTS of the study consist of concepts and ideas, related literature and studies, tools and equipment used in the construction of the project and expenses incurred in the fabrication of the project. The PROCESS of the study consists of designing the project, acquisition of needed materials, construction and assembly, testing and revising in case of some technical problems and revisions. The OUTPUT of the study is the finished and functional Electric Tri-Wheel Scooter. Upon the completion of the project, it was subjected to various tests before submitting it for final evaluation regarding its acceptability and performance (Figure 2).

Several literature reviews and informal surveys were done to see what type of electric scooters were already in existence as well as the cost of putting up such systems. Various configurations were examined in different types of environments and settings. It was found that an electric tri-wheeled scooter system was the ideal set-up in various types of applications, in it being a viable alternative transportation system that produces no harmful emissions.

Although there is a wide assortment of land transportation methods now available, more practical concerns such as cost and convenience quickly reduce the options and people typically choose automobiles for personal trips. There are also many mass transit options such as buses and trains but these do not provide the door-to-door service that many people desire. Although not as well accepted, human powered options, such as walking, bicycling and even roller blading to provide excellent individualized local transportation.

The transport sector plays a key role in economic development. In the past decades the transport planning model adopted by many countries, including the Philippines, prioritized the movement of cars and other motorized

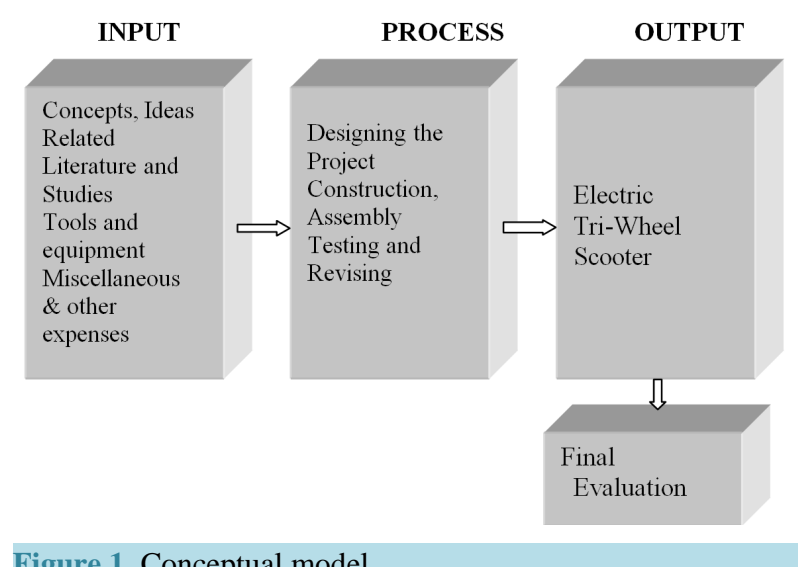

Figure 1. Conceptual model.

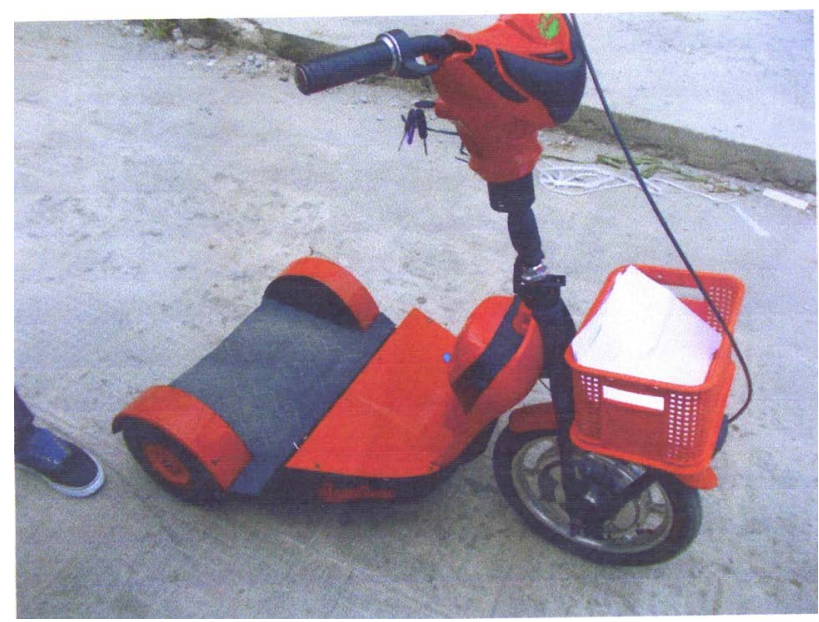

Figure 2. Picture of the finished project. 
vehicles to facilitate the growing demand for mobility of passengers and goods. As such, this has led to the development of more roads, and highways. Unfortunately, this has resulted in the preference for private motorized travel as less investments were made for public transport and non-motorized transport like walking and cycling, especially in the urban area [4].

In view of this, two (2) important policy directives related to climate change and sustainable transportation were issued from the Office of the President in December 2008 and January 2009. First, the Executive Order 774, which reorganized the Presidential Task Force on Climate Change (PTFCC) naming the President as the Chair and organizing 14 Task Groups that include a Task Group on Fossil Fuels with the aim to reduce fossil fuel consumption, reform the transport sector to include walking, cycling and other human-powered vehicles. The 2007 Philippine Climate Change Strategic Framework and Response Action Plan of the PTFCC in October 2007, though still undergoing stakeholder consultations, also included strategic directions to be taken to address climate change-related development issues, specifically, the introduction of technologies establishing low-carbon infrastructure for transport, energy, agriculture, industry and settlements.

It is for this reason that an intelligent electric scooter system can help the local industry do their part in meeting this environmental challenge. Several related studies were consulted in the conceptualization and development of the project.

Martin [5] stated that conventional automobiles operate with the use of internal combustion engines (ICEs) which run on fossil fuels as a source of energy. However, the conventional ICE provides poor fuel economy as well as producing air pollutants. A Plug-In Hybrid Electric Vehicle (PHEV) has the potential to run solely on the energy with zero emissions as long as it operates within its electric range. Active control techniques must be used in order to ensure optimum efficiency of the PHEV once the ICE is operated. He created a control strategy utilizing batteries as well as ultra-capacitors suitable for a PHEV configuration. The control strategy will be evaluated through numerical models under several under several driving cycles as well as emergency maneuvers in order to ensure its effectiveness in reducing fuel consumption and improve engine efficiency.

Baharin [6] made a solar powered bike. The concept of solar energy is that a high torque motor will be put on the bicycle which will be generated by the solar energy. The solar energy will be absorbed by the portable solar panel to generate the power. The power that been absorbed by the solar panel can be used directly by the motor if the power matches the power requirement. If not, the motor will use the power from a battery. When the bicycle is not in use during the day, the solar panel will charge the battery. The system will make the bicycle operate more efficiently.

Gocmen [7] developed a two-wheeled balancing electric vehicle. The system is able to operate in transporter mode and robotic mode. The first goal is to maintain stabilization in pitch dynamics. This study focused on designing and implementing a state feedback controller to stabilize system on transporter mode. The system moves forward when the driver leans forward in transporter mode. Thus velocity is fed back to the system. In addition, the study covered physical improvement, parameter calculations and mathematical model improvement.

All these related literature and studies were taken into careful consideration in the design and development of the Electric Tri-Wheeled Scooter. A work plan was laid out to design and execute the fabrication of the project at hand. The study was primarily concerned with the design and fabrication of the electric tri-wheel scooter out of locally available materials. Its application is limited to indoor and outdoor mobilization. It included a system analysis of what type of motor was to be used, the type of battery and sensor systems to be used. After a careful system analysis of each component specification was done, additional considerations with regards to the availability and cost of each of the needed parts were also considered.

Shown in Figure 2 is the finished prototype of the project.

In terms of costs, the project only incurred a total fabrication expense of Php 16, 279.00. As compared with its commercially available counterparts, it is substantially lower since the cheapest electric scooter in the market nowadays is Php 35,000 and above.

About forty-five (45) working days were consumed in the preparation and fabrication of the project. Upon completion of the project, it was subjected to a break in period of two (2) weeks continuous operation inside the school premises. The charging times and cycles of the battery were also observed during this period. An audio-video presentation was also prepared as a documentation procedure of the actual demonstration of the operation of the project. It included the actual assembly procedure as well as 2-week break in operation of the project captured in time-lapse form. After continuously testing the project on a varied number of parameters, an objective evaluation was undertaken by the researcher to test the acceptability and performance of the project in terms 
of the pre-determined criteria set forth in the conceptualization of the study. Shown in Table 1 is a 5-point Likert scale that was used to quantify responses of the evaluators, with 5 being the highest and 1 being the lowest.

A panel of experts in the field of Electrical and Electronics Technology/Engineering as well as Automotive Technology were chosen to evaluate the project. A discussion of the salient features of the project was given as well as an actual demonstration prepared by the researchers. The experts were composed of forty-six (46) experts, who were a mixture of educators in HEIs and professionals employed in different companies in the area of Bulacan.

\section{Results and Discussion}

The primary objective of the study is to develop an Electric Tri-Wheel Scooter and evaluate it in terms of acceptability and performance. A discussion of each of these criteria follow:

\subsection{Functionality}

Table 2 shows the evaluation results of the project in terms of its functionality. As shown in the tabular results all statements regarding the projects suitability, accurateness, interoperability, compliance and security were rated "highly acceptable, with mean ratings ranging from 4.65 to 4.75 .

The average mean rating of 4.72, interpreted as "highly acceptable", shows that the project was rated favorably by the respondents in terms of its functionality.

\subsection{Safety}

Table 3 shows the evaluation results of the project in terms of its safety. All statements regarding the projects safety were rated favorably, as evidenced by the average mean rating of 4.53 , interpreted as "highly acceptable.

\subsection{Durability}

In terms of its durability, Table 4 shows that the evaluators rated the statements favorably, as evidenced by the average mean rating of 4.70 interpreted as "highly acceptable.

\subsection{Aesthetics}

Based on the results of the evaluation, the projects' Aesthetics was rated "highly acceptable” as evidenced by

Table 1. Likert scale with corresponding verbal interpretation.

\begin{tabular}{cc}
\hline Scale & Verbal interpretation \\
\hline $4.21-5.00$ & Highly acceptable \\
$3.41-4.20$ & Acceptable \\
$2.61-3.40$ & Moderately acceptable \\
$1.81-2.60$ & Unacceptable \\
$1.00-1.80$ & Highly unacceptable \\
\hline
\end{tabular}

Table 2. Mean and descriptive ratings for the projects' functionality.

\begin{tabular}{|c|c|c|}
\hline Criteria & \multirow{2}{*}{ Mean } & \multirow{2}{*}{ Interpretation } \\
\hline Functionality & & \\
\hline 1) Ease of operation & 4.75 & Highly acceptable \\
\hline 2) Provides comfort and convenience & 4.65 & Highly acceptable \\
\hline 3) User-friendliness & 4.75 & Highly acceptable \\
\hline Average mean & 4.72 & Highly acceptable \\
\hline
\end{tabular}


the average mean rating of 4.72 (Table 5).

\subsection{Summary Findings}

As reflected in Table 6, all evaluation criteria set forth at the outset of the study were given favorable ratings of "very acceptable" by the panel of evaluators in terms of 1) functionality; 2) safety; 3) durability and 4) aesthetics.

In addition, it was determined that it was the appropriate design that integrated the most practical and adaptable design for a wide variety of applications. Finally, the project also functioned according to expectations, in being a cheaper alternative as compared with its commercially available counterparts.

Table 3. Mean and descriptive ratings for the projects' safety.

\begin{tabular}{|c|c|c|}
\hline Criteria & \multirow{2}{*}{ Mean } & \multirow{2}{*}{ Interpretation } \\
\hline Safety & & \\
\hline 1) Absence of sharp edges & 4.65 & Highly acceptable \\
\hline 2) Safety of use for the rider & 4.60 & Highly acceptable \\
\hline 3) Convenient to use on rough roads & 4.35 & Highly acceptable \\
\hline Average mean & 4.53 & Highly acceptable \\
\hline
\end{tabular}

Table 4. Mean and descriptive ratings for the projects' durability.

\begin{tabular}{|c|c|c|}
\hline Criteria & \multirow{2}{*}{ Mean } & \multirow{2}{*}{ Interpretation } \\
\hline Durability & & \\
\hline 1) Quality of materials & 4.75 & Highly acceptable \\
\hline 2) Quality of workmanship & 4.75 & Highly acceptable \\
\hline 3) Quality of design & 4.60 & Highly acceptable \\
\hline Average mean & 4.70 & Highly acceptable \\
\hline
\end{tabular}

Table 5. Mean and descriptive ratings for the projects' aesthetics.

\begin{tabular}{cccc}
\hline Criteria & Mean & Interpretation \\
\hline Aesthetics & & Highly acceptable \\
\hline 1) Color appeal & 4.75 & Highly acceptable \\
2) Attractiveness of design & 4.75 & Highly acceptable \\
3) Appropriateness of size & 4.60 & Highly acceptable \\
Average mean & $\mathbf{4 . 7 2}$ & \\
\hline
\end{tabular}

Table 6. Summary of responses.

\begin{tabular}{|c|c|c|}
\hline Criteria & Mean & Interpretation \\
\hline 1) Functionality & 4.72 & Highly acceptable \\
\hline 2) Safety features & 4.53 & Highly acceptable \\
\hline 3) Durability & 4.70 & Highly acceptable \\
\hline 4) Aesthetics & 4.71 & Highly acceptable \\
\hline Overall mean & 4.67 & Highly acceptable \\
\hline
\end{tabular}




\section{Recommendations}

In light of the significant findings derived from the development of this project, the following are the recommendations:

1) The Electric Tri Wheel Scooter is very affordable and as such, can be mass-produced to address the individual transport concerns as a viable alternative in cheap and clean transportation modes;

2) The project is installed with a signal light, a warning when the scooter is running;

3) A simple suspension is installed to lessen the vibration when travelling on rough roads;

4) A buzzer should be installed, so that it warns people within the vicinity that the scooter is running in reverse or is backing up; and

5) Further studies are done to expand the functions and capabilities of the project so as to further add additional features to the existing prototype.

\section{References}

[1] http://www.ucsusa.org/our-work/clean-vehicles/vehicles-air-pollution-and-human-health\#.VT8rpUsxHII

[2] Guinness World Records (2012) Best-Selling Electric Car.

[3] (2015) Holistically Defining e-Mobility: A Modern Approach to Systematic Literature Reviews.

[4] Fabian, H. and Gota, S. (2009) $\mathrm{CO}_{2}$ Emissions from the Land Transport Sector in the Philippines: Estimates and Policy Implications. Proceedings of the 17th Annual Conference of the Transportation Science Society of the Philippines.

[5] Martin, K. (2010) Plug-In Hybrid Electric Vehicle Control Strategies Utilizing Multiple Peaking Power Sources. Master's Thesis, University of Windsor, Canada.

[6] Baharin, M.A. (2010) Solar Bicycle. Faculty of Electrical and Electronics Engineering, University of Pahang, Malaysia.

[7] Gocmen, A. (2011) Designed a Two-Wheeled Electric Vehicle. Presented to the Academic Faculty of the Georgia Institute of Technology. 